\title{
Article
}

\section{Statins used for secondary prevention in patients with stroke reduce the risk of further ischaemic strokes and cardiovascular events}

Hill, James Edward and Hare, Marianne

Available at https://clok.uclan.ac.uk/31273/

Hill, James Edward orcid iconORCID: 0000-0003-1430-6927 and Hare, Marianne (2019) Statins used for secondary prevention in patients with stroke reduce the risk of further ischaemic strokes and cardiovascular events.

Evidence-based nursing . ISSN 1367-6539

It is advisable to refer to the publisher's version if you intend to cite from the work. http://dx.doi.org/10.1136/ebnurs-2019-103136

For more information about UCLan's research in this area go to http://www.uclan.ac.uk/researchgroups/ and search for <name of research Group>.

For information about Research generally at UCLan please go to http://www.uclan.ac.uk/research/

All outputs in CLoK are protected by Intellectual Property Rights law, including Copyright law. Copyright, IPR and Moral Rights for the works on this site are retained by the individual authors and/or other copyright owners. Terms and conditions for use of this material are defined in the policies page. 
Category: Nursing issues

Study type: Systematic review and network meta-analysis

Author's declarative title: Statins used for secondary prevention with stroke patients reduces the risk of ischemic strokes and cardiovascular events.

Commentary on: Tramacere, I., Boncoraglio, G.B., Banzi, R. et al. Comparison of statins for secondary prevention in patients with ischemic stroke or transient ischemic attack: a systematic review and network meta-analysis. BMC Med 17, 67 (2019) doi:10.1186/s12916-019-1298-5

Commentary Implications for practice and research

- The secondary use of statins is effective in reducing the absolute risk of ischemic stroke and cardiac events in patients who have previously had an ischemic stroke or transient ischemic attack.

- There is still uncertainty about which statin is the most effective.

\section{Context}

Stroke is one of the major causes of worldwide death and disability with one in four people predicted to experience a stroke within their lifetime (1). After a stroke or a Transient Ischemic Attack [TIA] there remains a substantial long-term risk of recurrent stroke (2). It is recommended that statins should be used to reduce the risk of recurrent stroke with ischemic stroke or TIA presumed to be of atherosclerotic origin (3). This review aimed to summarize the current evidence on the benefits and harms of the varying statins used for secondary prevention for these patients (4).

\section{Methods}

The review carried out a comprehensive literature search on multiple databases from January-2008 to July-2017. Studies prior to 2008 were identified through two Cochrane systematic reviews. Only randomised controlled trials [RCTs] which compared any single statin compared to placebo/no statin or another statin in adults with stroke or TIA from all clinical settings were included. A robust screening process, data extraction and quality assessment (Cochrane collaboration criteria and GRADE) was carried out by two independent reviewers with arbitration by a third reviewer. An appropriate synthesis was carried out using a pairwise and network meta-analyses, and trial sequential analyses. 


\section{Findings}

Four different statins (Atorvastatin, Simvastatin, Rosuvastatin and Pravastatin) were compared to placebo/no statin. The review found that there was not strong evidence to indicate that one statin was better than the other for the outcomes assessed within this review. Atorvastatin $80 \mathrm{mg} /$ day appeared to have a statistically significant benefit for risk of ischemic stroke, ischemic stroke \& TIA and cardiovascular events and Simvastatin $40 \mathrm{mg} /$ day appeared to have a statistically significant benefit for risk of cardiovascular events.

There was not strong evidence that statins have an effect on reducing the risk of stroke (ischemic or hemorrhagic), all cause-mortality, hemorrhagic stroke and rise in creatine kinase compared to placebo/no statin.

There was high quality evidence that statins statistically and clinically significantly reduced the risk of ischemic strokes and cardiac event.

For both outcomes of risk of ischemic attack and cardiac events, the authors of the review have a lot of confidence that the true effect is similar to the estimated effect. The estimated effect from this review result in the number needed to treat being 63 (95\%.CL,39-167) patients to prevent one additional ischemic attack and 19 (95\%.CL,15-28) people to prevent one additional cardiac event. These findings are similar to other published systematic reviews for these outcomes and are clinically significant.

\section{Commentary}

This review is of high quality and provides an accurate and comprehensive summary of the results of the available studies that address the question of interest. The findings from this review were limited by there being a lack of evidence in specific outcomes and no head-to-head comparisons of statins which has resulted in some of the comparisons being underpowered. Furthermore, there was also a scarcity of evidence for patients who were at high risk which result in these findings being less applicable for this subpopulation.

When choosing statins for a secondary preventative measure for people who have had a stroke, there is currently limited evidence to indicate for the outcomes assessed in this review one over the other. Where these uncertainties still exist, there are other important aspects which can be taken into consideration when deciding which statin to use such as patient preference, pharmacokinetic properties, safety, cost and patient characteristics (3)..

For the outcomes of the risk of all stroke, all cause-mortality, hemorrhagic stroke, rise in creatine kinase and the effect of stroke subtypes at inclusion, treatment dose, time from the first ischemic event to randomization there is still uncertainty. Based on this uncertainty there is a requirement for further research on these outcomes, 
specifically regarding the effect on the risk of hemorrhagic stroke as there seems to be the greatest uncertainty around this outcome.

\section{References}

1. Feigin VL, Norrving B, Mensah GA. Global Burden of Stroke. Circulation Research. 2017;120(439-448).

2. Edwards JD, Kapral MK, Fang J, Swartz RH. Long-term morbidity and mortality in patients without early complications after stroke or transient ischemic attack. CMAJ. 2017;189(29):E954-E61.

3. Kernan WN, Ovbiagele B, Black HR, Bravata DM, Chimowitz MI, Ezekowitz MD, et al. Guidelines for the prevention of stroke in patients with stroke and transient ischemic attack: a guideline for healthcare professionals from the American Heart Association/American Stroke Association. Stroke. 2014;45(7):2160-236.

4. Tramacere I, Boncoraglio GB, Banzi R, Del Giovane C, Kwag KH, Squizzato A, et al. Comparison of statins for secondary prevention in patients with ischemic stroke or transient ischemic attack: a systematic review and network meta-analysis. BMC Med. 2019;17(1):67.

\section{Commentator details}

Name: James Edward Hill

Affiliation: University of Central Lancashire

Correspondence address:

University of Central Lancashire,

Preston,

Lancashire

PR1 2HE

Email: Jehill1@uclan.ac.uk

\section{Competing interests}

I have no conflicts of interest with any aspect of this publication 